American Journal of Neuroscience 3 (1): 10-16, 2012

ISSN 1948-9900

C 2012 Science Publications

\title{
Reading Acquisition and Phonological Awareness: Beyond the Segmental Level
}

\author{
${ }^{1}$ Cyrille Magne and ${ }^{2}$ Melissa Brock \\ ${ }^{1}$ Department of Psychology, \\ ${ }^{2}$ Program in Literacy Studies, \\ Middle Tennessee State University, Murfreesboro TN, 37132, USA
}

\begin{abstract}
Problem statement: Phonological awareness is a major contributor to reading development. While the literature has primarily focused on the segmental aspect of phonology, suprasegmental information, namely prosody, has been largely underexplored in comparison. Approach: This review focuses on recent behavioral and neuroimaging studies on the development of prosody sensitivity during early childhood and the influence of prosody on reading processes. Results: Overall, the literature highlights the importance of prosodic information, not only during reading acquisition in children, but also during silent reading in skilled readers. This contribution is independent of segmental phonology, but may influence the development of phonological awareness. Conclusion: The current findings open the door to the development of new reading assessment tools that can allow determining whether pre-literacy students are at risk for reading development difficulties.
\end{abstract}

Key words: Prosody sensitivity, implicit prosody, literacy development, reading acquisition, neuroimaging, Optical Topography (OT), Event-Related Potential (ERP)

\section{INTRODUCTION}

In a recent article in American Journal of Neuroscience, offers an overview of the phonological deficit theory in individuals with developmental dyslexia. In particular, the review highlights the link between reading abilities and performances on tasks requiring phonological awareness, phonological shortterm memory or rapid automatized naming. In addition, as pointed out by the author, it remains to be determined whether or not the difficulty that individuals with dyslexia encounter with phonological processing is the result of a more basic auditory and/or visual deficit.

While the phonological deficit theory has been widely recognized (Ramus, 2003), it is worth noting that most studies deal primarily with the segmental aspect of phonology (i.e., the speech sounds, their internal composition and their combination). In contrast, the suprasegmental aspects of phonology, namely prosody, have not been explored to the same extent, perhaps because deficits of speech perception are not always found in individuals with phonological impairment (Joanisse et al., 2000). Prosody plays an important role in speech perception as it conveys patterns of stress, accentuation and intonation, through variations of intensity, duration and fundamental frequency in the acoustic signal. Prosody not only conveys emotional information regarding the mood of the speaker (Besson et al., 2002), but also linguistic information that guides language comprehension at the word, sentence and discourse levels (Alter, 2009).

Many studies have highlighted the importance of prosodic sensitivity (i.e., the awareness of the suprasegmental features of phonology), not only for speech perception in adults (Cutler and Norris, 1988) by also for language acquisition in children (Jusczyk, 1999). In addition, recent findings highlight a potential relationship between prosodic sensitivity and the development of reading skills (Wood and Connelly, 2009). The aim of the current paper is to give a current state of the literature on the role of prosody during reading acquisition and comprehension. We will first review the development of sensitivity to prosodic cues from birth to early childhood, prior to discussing the main findings highlighting a link between prosody perception and reading. We will conclude by offering some potential future directions of research.

\section{DEVELOPMENT OF PROSODY SENSITIVITY}

In infants, many behavioral studies have been conducted using the head turning technique (Kuhl,

Corresponding Author: Cyrille Magne, Department of Psychology, Middle Tennessee State University, PhD, 1301 East Main St. Murfreesboro, TN 37132, USA Tel: 615-898-5599 
Am. J. Neuroscience 3 (1): 10-16, 2012

2004). This procedure involves first familiarizing the infant with a repeated stimulus. Then, the length of time the infant looks in the direction of the familiar stimulus (or the speaker through which it is presented) is compared to how long the infant looks in the direction of a novel stimulus, the assumption being that the infant will look longer in the direction of the familiar stimulus. Using this procedure, several studies showed that young infants, including newborns, can discriminate between utterances from their mother tongue and those from a language from a different class of speech rhythm (Mehler et al., 1988; Moon et al., 1993; Nazzi et al., 1998). Moreover, 9-month-old American infants showed a preference for listening to words starting with a strong syllable, the most common stress pattern in English, compared to a weak syllable (Jusczyk et al., 1993). In contrast, the ability to discriminate words starting with an unstressed syllable appears to develop later, around the age of 10.5 months, as this may require the use of additional sources of information and/or different strategies (Jusczyk et al., 1999). Other recent studies showed that prosodic cues may also be important at an early age to detect new information in the context of a conversation (Grassmann and Tomasello, 2007; 2010).

It should be noted that such studies require a certain amount of attention and motor control on the part of the young participants (Sambeth et al., 2008). In recent years, several studies have employed neuroimaging methods, which are not as reliant on attention and motor responses, to investigate the perception of prosodic cues during the first years of life. Sambeth et al. (2008) used Magnetoencephalography (MEG) to compare the brain responses of sleeping newborns to natural and manipulated speech stimuli. The natural stimuli consisted of Finnish Christmas carols that were sung or spoken, while manipulated versions were created by either flattening the intonation (thus rendering the speech monotonic yet still intelligible) or filtering out the formants (thus rendering semantic information unintelligible while preserving prosodic information). Results indicated that the amplitude of a particular brain response, the $\mathrm{P} 1 \mathrm{~m}$, was larger for natural than manipulated speech, which the authors interpreted as demonstrating that newborns respond to some prosodic cues.

In another study, Pannekamp et al. (2006) monitored 8-month-old infants' processing of prosodic boundaries using the Event-Related Potential (ERP) method. Infants were presented with sentences in which an intonational phrase boundary (IPh) was either present or absent after the first verb. Results revealed that IPhs elicited a positive ERP component similar to the Closure Positive Shift (CPS) previously observed in adults
(Steinhauer et al., 1999), hence suggesting that the neural substrate for the perception of prosodic phrase boundaries is already in place in 8 month-old infants.

Homae et al. (2006) used near-infrared Optical Topography (OT) to study prosodic processing in 3month-old infants while they were listening to normal and flattened Japanese sentences. Results indicated bilateral activation of the temporo-parietal cortex in response to both normal and flattened utterances. However, the right temporo-parietal region showed significantly higher activation in response to the normal, as compared to the flattened. This not only suggests that this region is more sensitive to the pitch contours of normal prosodic speech than the even pitch of flattened speech, but that a functional differentiation between the two hemispheres is present even in infants as young as 3 months old. In a follow-up experiment with 10-month-old infants (Homae et al., 2007), the authors found the opposite pattern of response in the right temporoparietal region (i.e., greater activation in response to flattened speech compared to normal speech), as well as the recruitment of additional bilateral prefrontal regions in both conditions that were not observed in 3-month-old infants. Thus, a functional reorganization of the mechanisms involved in processing information related to intonation seems to occur between the ages of 3 months and 10 months.

Wartenburger et al. (2007) explored the differential contributions of the left and right hemispheres during the prosodic processing of German 4-year-olds using Near-Infrared Spectroscopy (NIRS). They used normal and flattened speech stimuli as well as a hummed condition in which the phonological, semantic and syntactic information was filtered out but the intonation contour preserved. The authors found greater activation in the left frontal and temporal regions during normal speech and greater activation in the right frontotemporal regions during the hummed and flattened conditions. Thus, this study revealed that a right hemispheric specialization for prosodic processing, similar to that which has been observed in adults (Friederici and Alter, 2004; Baum and Pell, 1999; Meyer et al., 2002; 2003; Plante et al., 2002; Hesling et al., 2005), is also present in 4-year-olds.

Together, the studies aforementioned provide valuable insight into the processing of linguistic prosody during the first years of life and suggest that very early in life, the neural foundations of prosodic processing begin to resemble the neural correlates observed in adulthood. In addition, they suggest that prosody sensitivity develops and may be in place, before emergence of literacy. 
Am. J. Neuroscience 3 (1): 10-16, 2012

\section{THE RELATIONSHIP BETWEEN PROSODY SENSITIVITY AND READING SKILLS}

Over the past 10 years, the relationship between prosody and reading has been investigated by studying: the characteristics of reading prosody (i.e., reading with expression) in young readers, the relationship between prosody sensitivity and word reading, rhythm sensitivity in individuals with dyslexia and the online influence of implicit prosody during silent reading.

Schwanenflugel et al. (2004) studied the relationship between second and third graders' reading prosody and their decoding and reading comprehension skills. They recorded the children's oral reading of a passage and analyzed the duration of the pauses, sentence-final pitch declination and the overall prosodic contour. Decoding and reading comprehension skills were measured using standardized tests. They found that good readers had more adult-like intonation and shorter intra- and inter-sentential pauses. Miller and Schwanenflugel (2006) replicated these results using a passage containing more syntactically complex sentences. In addition, the data suggested that different prosodic features affect distinct aspects of the reading process. In particular, they found that intonation accounted for unique variance in reading comprehension, but pause duration did not. In a longitudinal study, the same author found that the acquisition of adult-like intonation during grade 1 and 2 was a predictor of later reading comprehension during grade 3 (Miller and Schwanenflugel, 2008).

The relationship between prosody sensitivity and reading skill has also been investigated using several custom prosody perception tasks. Whalley and Hansen (2006) developed two prosodic measures. The "DEEdee task" assessed children's ability to rely on stress, rhythm and intonation at the phrase level by requiring them to match a spoken phrase to its DEEdee version in which the prosody of the original phrase was preserved but each syllable was replaced with the reiterative syllable "dee". "The compound noun task" measured prosodic sensitivity at the word level and required students to use intonation, phrasing and pauses to distinguish between compound nouns and noun phrases (e.g., 'highchair' or 'high chair'). Performance on the DEEdee task predicted unique variance in reading comprehension while performance on the compound noun task predicted unique variance in word identification accuracy.

Wood (2006) developed the "stress mispronunciation task" to investigate the relationship between prosody sensitivity, phonological awareness and reading at the word level. In this task, 5-7 year-old children listened to a target word that had been mispronounced with a reversed stress pattern and identified the corresponding picture. Thus, to accomplish the task, children had to mentally apply the correct stress pattern to the words. The results revealed that performance on the stress mispronunciation task was related to spelling scores, even after controlling for phonological awareness and vocabulary. Using similar mispronunciation tasks in 5-7 year-old children, sensitivity to speech rhythm was found to account for some amount of unique variance in word reading ability after controlling for age, vocabulary and phonological awareness (Holliman et al., 2008) as well as short-term memory and non-speech rhythm (Holliman et al., 2010a). In addition, performance on the mispronunciation task was predictive of reading performance one year later in 5-8 year-old children (Holliman et al., 2010b). Interestingly, in a recent study, Holliman et al. (2012) found that 10 year-old children identified as poor readers ( 2 years behind their chronological age) performed significantly lower on the mispronunciation task than their chronological agematched peers. Based on these findings, the authors argued that insensitivity to speech rhythm could be used as an early indicator of potential reading disorders.

Goswami et al. (2002) developed a beat detection task to investigate rhythm sensitivity in individuals with dyslexia. Stimuli consisted of non-speech sound sequences made of square waves with varying rise times (i.e., the time required for the amplitude to move from minimum to maximum). After being trained on the shortest and longest rise-time stimuli, children performed a categorization task on subsequent sound sequences with rise-time varying between the two extremes. Results showed differences in rise-time perception between individuals with dyslexia and control children who were matched either by age or reading level. In addition, performance on the rise time discrimination task accounted for $25 \%$ of the variance in reading and spelling measures. Sensitivity to rise time was also found to predict phonological awareness and reading acquisition in Spanish and Chinese children, suggesting that it may be a "languageuniversal sensory deficit" (Goswami et al., 2011). This deficit may subsist past childhood, as difficulty in risetime perception has also been found in adults with dyslexia using similar stimuli (Thomson et al., 2006) and speech stimuli (Leong et al., 2011).

Goswami (2002) proposed that rise time is a key parameter for detecting vowel onset in speech. The findings thus suggest that dyslexia results from a nonspeech rise time processing deficit, which leads to difficulty in acquiring appropriate phonological 
representations. In line with this theory, a recent study demonstrated that sensitivity to musical meter was related to rise time perception as well as phonological awareness and literacy development (Huss et al., 2011). This basic sensory deficit may be caused by an increased difficulty of neural oscillations within the auditory cortex to efficiently phase-lock with the amplitude envelop (i.e., the form of the variation of amplitude) of the speech signal that carries suprasegmental information (Goswami, 2011; Hamalainen et al., 2012).

While the aforementioned studies strongly suggest that prosody sensitivity plays an important role in reading development, another line of research supports the Implicit Prosody Hypothesis (Fodor and Ferreira, 1998; Fodor, 1998). This theory proposes that suprasegmental phonological information affects the online processing of sentences during silent reading. For instance, using the EEG method, Steinhauer and Friederici (2001) and Steinhauer (2003) found that the CPS component (elicited by intonational phrase boundaries during spoken sentences) was also observed during silent reading when implicit intonational phrase boundaries were indicated by commas.

In addition to intonation, speech rhythm may also be implicitly recalled during reading. Ashby and Clifton (2005) measured eye movements while participants read sentences containing critical words with one or two stressed syllables. Words with two stresses were associated with longer reading times and more eye fixations. In another series of eyetracking experiments by Breen and Clifton (2011), participants took longer to read words with a stress pattern that did not match the expectation set by the sentence context.

Magne et al. (2010) also studied the influence of implicit speech rhythm on written word recognition using EEG. Participants were visually presented with lists of five bisyllabic words. The last word of each list had either the same stress pattern or the opposite stress pattern as the previous four words. Final words that did not match the stress pattern of the previous words elicited an increased N400 component. Since the N400 is usually considered to reflect access to semantic memory (Kutas and Federmeier, 2011), the authors proposed that the stress pattern of a word is automatically processed during silent reading in English and influences its semantic processing. Interestingly, speech rhythm sensitivity has also been found to influence reading processes in Chinese (Luo and Zhou, 2010), though this language is not usually considered as stresstimed (i.e., with regular duration between successive stressed syllables) as English or German. Taken together, these results show that information regarding the stress pattern of a word is part of its representation and automatically activated during silent reading.

\section{CONCLUSION}

Past research on prosody has highlighted its important role for many aspects of speech perception and language comprehension. It is thus not surprising that a better understanding of the role of different prosodic features may have many important implications. Overemphasizing the prosodic component (for instance, singing and listening to songs) may also enhance the learning of a foreign language (Pawanchik et al., 2010). In addition, a better understanding of prosody is relevant for speech processing technologies such as automatic speech recognition or text-to-speech synthesis. Accurate modeling of the pitch contour (conveying information regarding stress and intonation) is particularly important to preserve an accurate representation of the prosody of the speech signal for speech recognition (Chomphan, 2010; 2011; Faycal et al., 2010) and speech processing by cochlear implant (Rouiha et al., 2008).

In the present review, we argue that an increasing number of recent studies demonstrate that prosody may also be a key player in the processing of the visual form of language (i.e., reading). Prosodic information may especially be important for the acquisition of accurate phonological representations of one's native language and may still be used implicitly by skilled readers during the reading process. It should be noted, however, that a majority of the studies reviewed here used tasks measuring prosodic sensitivity at the word level. It thus remains to be determined whether prosody sensitivity at the sentence level plays a role in reading. Still, we believe that the existing results already have potential implications for classroom practice and suggest that developing oral language skills and word pronunciation (for instance through the use of creative drama activities, as found by Ulas (2008) should perhaps be a main focus in the primary school years. In addition, because prosodic sensitivity is well developed in typical children by the time literacy instruction starts, this new literature opens the door to the development of new assessment tools for early detection of children at risk for reading difficulties.

\section{ACKNOWLEDGEMENT}

The researchers would like to thank Reyna Gordon for helpful comments on an earlier version of the manuscript. 


\section{REFERENCES}

Alter, K.U., 2009. Brain Talk: Discourse with and in the Brain. 1st Edn., Lunds Universitet, Lund, ISBN: 9789163355615 , pp: 334.

Ashby, J. and C. Clifton, 2005. The prosodic property of lexical stress affects eye movements during silent reading. Cognition, 96: B89-B100. DOI: 10.1016/j.cognition.2004.12.006

Baum, S.R. and M.D. Pell, 1999. The neural bases of prosody: Insights from lesion studies and neuroimaging. Aphasiology, 13: 581-608. DOI: 10.1080/026870399401957

Besson, M., C. Magne and D. Schon, 2002. Emotional Prosody: Sex differences in sensitivity to speech melody. Trends Cogn. Sci., 6: 405-407. DOI: 10.1016/S1364-6613(02)01975-7

Breen, M. and C. Jr. Clifton, 2011. Stress matters: Effects of anticipated lexical stress on silent reading. J. Memory Lang., 64: 153-170. DOI: 10.1016/j.jml.2010.11.001

Chomphan, S., 2010. Structural modeling of fundamental frequency contour for Thai expressive speech. J. Comput. Sci., 6: 330-335. DOI: 10.3844/jcssp.2010.330.335

Chomphan, S., 2011. Analytical study on fundamental frequency contours of Thai tones using tonegeometrical model. J. Comput. Sci., 7: 379-386. DOI: $10.3844 /$ jcssp.2011.379.386

Cutler, A. and D. Norris, 1988. The role of strong syllables in segmentation for lexical access. J. Exp. Psychol., 14: 113-121. DOI: 10.1037/00961523.14.1.113

Faycal, Y., B. Mesaoud and B. Lotfi, 2010. Prosody modification of standard Arabic speech using combining synchronous overlap and add with fixed-synthesis algorithm and multi level discrete wavelet transform. J. Comput. Sci., 6: 392-405. DOI: $10.3844 /$ jcssp.2010.392.405

Fodor, J.D. and F. Ferreira, 1998. Reanalysis in Sentence Processing. 1st Edn., Springer, Dordrecht, ISBN: 9780792350996, pp: 412.

Fodor, J.D., 1998. Learning to parse? J. Psycholinguist. Res., 27 2 $285-319 . \quad$ DOI: 10.1023/A: 1023258301588

Friederici, A.D. and K. Alter, 2004. Lateralization of auditory language functions: A dynamic dual pathway model. Brain Lang., 89: 267-276. DOI: 10.1016/S0093-934X(03)00351-1

Goswami, U., 2011. A temporal sampling framework for developmental dyslexia. Trends Cogn. Sci., 15: 3-10. DOI: $10.1016 /$ j.tics.2010.10.001
Goswami, U., H.L. Wang, A. Cruz, T. Fosker and N. Mead et al., 2011. Language-universal sensory deficits in developmental dyslexia: English, Spanish and Chinese. J. Cogn. Neurosci., 23: 325337. DOI: $10.1162 /$ jocn. 2010.21453

Goswami, U., J. Thomson, U. Richardson, R. Stainthorp and D. Hughes et al., 2002. Amplitude envelope onsets and developmental dyslexia: A new hypothesis. P. Nat. Acad. Sci. USA, 99: 10911-10916. DOI: 10.1073/pnas.122368599

Grassmann, S. and M. Tomasello, 2007. Two-year-olds use primary sentence accent to learn new words. J. Child Lang., 34: 677-687. DOI: 10.1017/S0305000907008021

Grassmann, S. and M. Tomasello, 2010. Prosodic stress on a word directs 24-month-olds' attention to a contextually new referent. J. Prgmatics, 42: 30983105. DOI: 10.1016/j.pragma.2010.04.019

Hamalainen, J.A., A. Rupp, F. Soltész, D. Szücs and U. Goswami, 2012. Reduced phase locking to slow amplitude modulation in adults with dyslexia: An MEG study. NeuroImage, 59: 2952-2961. DOI: 10.1016/neuroimage.2011.09.075

Hesling, I., S. Clement, M. Bordessoules and M. Allard, 2005. Cerebral mechanisms of prosodic integration: Evidence from connected speech. NeuroImage, 24: 937-947. DOI: 10.1016/j.neuroimage.2004.11.003

Holliman, A.J., C. Wood and K. Sheehy, 2008. Sensitivity to speech rhythm explains individual differences in reading ability independently of phonological awareness. Brit. J. Dev. Psychol., 26: 357-367. DOI: 10.1348/026151007X241623

Holliman, A.J., C. Wood and K. Sheehy, 2010a. The contribution of sensitivity to speech rhythm and non-speech rhythm to early reading development. Educ. Psychol., 30: 247-267. DOI: 10.1080/01443410903560922

Holliman, A.J., C. Wood and K. Sheehy, 2010b. Does speech rhythm sensitivity predict children's reading ability 1 year later? J. Educ. Psychol., 102: 356-366. DOI: $10.1037 / \mathrm{a} 0018049$

Holliman, A.J., C. Wood and K. Sheehy, 2012. A crosssectional study of prosodic sensitivity and reading difficulties. J. Res. Reading, 35: 32-48. DOI: 10.1111/j.1467-9817.2010.01459.x

Homae, F., H. Watanabe, T. Nakano and G. Taga, 2007. Prosodic processing in the developing brain. Neurosci. Res., 59: 29-39. DOI: 10.1016/j.neures.2007.05.005 
Homae, F., H. Watanabe, T. Nakano, K. Asakawa and G. Taga, 2006. The right hemisphere of sleeping infant perceives sentential prosody. Neurosci. Res., 54: 276-280. DOI: 10.1016/j.neures.2005.12.006

Huss, M., J.P. Verney, T. Fosker, N. Mead and U. Goswami, 2011. Music, rhythm, rise time perception and developmental dyslexia: Perception of musical meter predicts reading and phonology. Cortex, 47: 674-689. DOI: 10.1016/j.cortex.2010.07.010

Joanisse, M.F., F.R. Manis, P. Keating and M.S. Seidenberg, 2000. Language deficits in dyslexic children: Speech perception, phonology and morphology. J. Exp. Child Psychol., 77: 30-60. DOI: $10.1006 /$ jecp.1999.2553

Jusczyk, P.W., 1999. How infants being to extract words from speech. Trends Cogn. Sci., 3:323-328. DOI: $10.1016 / \mathrm{S} 1364-6613(99) 01363-7$

Jusczyk, P.W., A. Cutler and N. Redanz, 1993. Infants' Preference for the predominant stress patterns of English words. Child Dev., 64:675-687. DOI: $10.2307 / 1131210$

Jusczyk, P.W., D. Houston and M. Newsome, 1999. The beginnings of word segmentation in Englishlearning infants. Cogn. Psychol., 39: 159-207. DOI: $10.1006 / \operatorname{cogp} .1999 .0716$

Kuhl, P.K., 2004. Early language acquisition: Cracking the speech code. Nat. Rev. Neurosci., 5: 831-843. DOI: $10.1038 / \mathrm{nrn} 1533$

Kutas, M. and K.D. Federmeier, 2011. Thirty years and counting: finding meaning in the N400 component of the Event-Related Brain Potential (ERP). Annu. Rev. Psychol., 62: 621-647. DOI: 10.1146/annurev.psych.093008.131123

Leong, V., J. Hamalainen, F. Soltesz and U. Goswami, 2011. Rise time perception and detection of syllable stress in adults with developmental dyslexia. J. Mem. Lang., 64: 59-73. DOI: 10.1016/j.jml.2010.09.003.

Luo, Y. and X. Zhou, 2010. ERP evidence for online processing of rhythmic pattern during Chinese sentence reading. NeuroImage, 49: 2836-2849. DOI: $10.1016 /$ j.neuroimage.2009.10.008

Magne, C., R.L. Gordon and S. Midha, 2010. Influence of metrical expectancy on reading words: An ERP study. Middle Tennessee State University, Murfreesboro, TN.

Mehler, J., P. Jusczyk, G. Lambertz, M. Halsted and J. Bertoncini et al., 1988. A precursor of language acquisition in young infants. Cognition, 29: 143178. DOI: 10.1016/0010-0277(88)90035-2
Meyer, M., K. Alter and A.D. Friederici, 2003. Towards the cerebral substrates of sentence-level syntactic and prosodic processing. J. Neurolinguist., 16: 277-300. DOI: 10.1016/S09116044(03)00026-5

Meyer, M., K. Alter, A.D. Friederici, G. Lohmann and D.Y. Von Cramon, 2002. FMRI reveals brain regions mediating slow prosodic modulations in spoken sentences. Hum. Brain Mapp., 17: 73-88. DOI: $10.1002 / \mathrm{hbm} .10042$

Miller, J. and P.J. Schwanenflugel, 2006. Prosody of syntactically complex sentences in the oral reading of young children. J. Educ. Psychol., 98: 839-853. DOI: 10.1037/0022-0663.98.4.839

Miller, J. and P.J. Schwanenflugel, 2008. A longitudinal study of the development of reading prosody as a dimension of oral reading fluency in early elementary school children. Read. Res. Quart., 43:336-354. DOI: 10.1598/RRQ.43.4.2

Moon, C., R.P. Cooper and W.P. Fifer, 1993. Twodays-olds prefer their native language. Infant Behav. Dev., 16:495-500. DOI: 10.1016/01636383(93)80007-U

Nazzi, T., C. Floccia and J. Bertoncini, 1998. Discrimination of pitch contours by neonates. Infant Behav. Dev., 21:779-784. DOI: 10.1016/S0163-6383(98)90044-3

Pannekamp, A., C. Weber and A.D. Friederici, 2006. Prosodic processing at the sentence level in infants. NeuroReport, 17: 675-678. DOI: 10.1097/00001756-200604240-00024

Pawanchik, S., A.A. Kamil and F.H. Yahaya, 2010. Indigenous students and the learning of English. J. Soc. Sci., 6: 443-446. DOI: 10.3844/jssp.2010.443.446

Plante, E., M. Creusere and C. Sabin, 2002. Dissociating sentential prosody from sentence processing: Activation interacts with task demands. Neuroimage, 17: 401-410. DOI: 10.1006/nimg.2002.1182,

Ramus, F., 2003. Developmental dyslexia: Specific phonological deficit or general sensorimotor dysfunction? Curr. Opin. Neurobiol., 13: 212-218. DOI: 10.1016/S0959-4388(03)00035-7

Rouiha, K., D. Bachir and B. Ali, 2008. Analysis of speech processing strategies in cochlear implants. J. Comput. Sci., 4: 372-374. DOI: 10.3844/jcssp.2008.372.374

Sambeth, A., K. Ruohio, P. Alku, V. Fellman and M. Huotilainen, 2008. Sleeping newborns extract prosody from continuous speech. Clin. Neurophysiol., 119: 332-341. DOI: 10.1016/j.clinph.2007.09.144 
Schwanenflugel, P.J., A.M. Hamilton, M.R. Kuhn, J.M.Wisenbaker and S.A. Stahl, 2004. Becoming a fluent reader: Reading skill and prosodic features in the oral reading of young readers. J. Educ. Psychol., 96: 119-129. DOI: 10.1037/00220663.96.1.119

Steinhauer, K. and A.D. Friederici, 2001. Prosodic boundaries, comma rules and brain responses: The closure positive shift in ERPs as a universal marker for prosodic phrasing in listeners and readers. J. Psycholinguist. Res., 30: 267-295. DOI: 10.1023/A:1010443001646

Steinhauer, K., 2003. Electrophysiological correlates of prosody and punctuation. Brain Lang., 86:142-164. DOI: 10.1016/S0093-934X(02)00542-4

Steinhauer, K., K. Alter and A.D. Friederici, 1999. Brain potentials indicate immediate use of prosodic cues in natural speech processing. Nat. Neurosci., 2: 191-196. DOI: 10.1038/5757

Thomson, J.M., B. Fryer, J. Maltby and U. Goswami, 2006. Auditory and motor rhythm awareness in adults with dyslexia. J. Res. Read., 29: 334-344. DOI: $10.1111 / \mathrm{j} .1467-9817.2006 .00312 . x$
Ulas, A.H., 2008. Effects of creative, educational drama activities on developing oral skills in primary school children. Am. J. Applied Sci., 5: 876-880. DOI: 10.3844/ajassp.2008.876.880

Wartenburger, I., J. Steinbrink, S. Telkmeyer, M. Friedrich and A. Friederici et al., 2007. The processing of prosody: Evidence of interhemispheric specialization at the age of four. NeuroImage, 34: 416-425. DOI: 10.1016/j.neuroimage.2006.09.009

Whalley, K. and J. Hansen, 2006. The role of prosodic sensitivity in children's reading development. J. Res. Read., 29: 288-303. DOI: 10.1111/j.14679817.2006.00309.x

Wood, C. and V. Connelly, 2009. Contemporary Perspectives on Reading and Spelling. 1st Edn., Taylor and Francis, London, ISBN: 0415497175, pp: 292.

Wood, C., 2006. Metrical stress sensitivity in young children and its relationship to phonological awareness and reading. J. Res. Read., 29: 270-287. DOI: 10.1111/j.1467-9817.2006.00308.x 